by the Association of Clinical Pathologists. It might be worth while for the editor to consider this possibility, reserving the book for reviews rather than recipes, but there is no doubt that in its present form this is a book to be bought for the clinical laboratory.

\section{Clinical Genodermatology}

Thomas ButTerworth, A.B., M.D., MED.SC.M. and LYON P. STREAN, D.D.S., M.SC., PH.D., F.A.P.H.A., F.A.A.A.S. Introduction by James E. Wright. Pp. xxi + 221. 99 illustrations. London: Baillière, Tindall \& Cox. 1962. ro8s.

The publication in 1933 of Cockayne's 'Inherited Abnormalities of the Skin and its Appendages' was the most important landmark in the study of the genetic factor in dermatology. Unfortunately it has been out of print for many years. Since then the only major work of reference has been Touraine's book published in French in 1955. A good new book on the subject in English is much needed and this volume is a not unworthy attempt to fill the gap. It starts with a valuable nine-page introduction by the Professor of Genetics in the Pennsylvania State University in which the elements of genetics are clearly and simply explained and the most important technical terms are defined. The body of the book consists of brief illustrated descriptions of the familial disorders of the skin and mucous membranes including a simple account of their modes of hereditary transmission and a very brief bibliography. Wisely they are arranged morphologically rather than aetiologically. The text is good and most of the black-and-white photographs are useful. A number of genodermatoses which should have been described are omitted. These include the Naegeli type of incontinentia pigmenti, Rud's syndrome, and some of the rarer varieties of epidermolysis bullosa. In particular, Touraine's ideas of poly-fibromatosis and polykeratosis ought to have been discussed. The index is satisfactory. The volume is attractively produced. It may be that the greatest problem the authors had to face was one of length. For a book of this size it is very good. Dermatologists would probably have preferred a longer account of the genetics of each disorder with less general description but for those who are not specialists the proportions used may well be more helpful. This is a valuable work of reference and no dermatologist nor medical library can afford to be without it. Great skill in the writing has made a difficult subject seem simple. Further editions are likely to be needed and it will then be possible to include those syndromes which have, so far, been omitted.

\section{Inhalation Anesthetics and Carbohydrate Meta- bolism}

Nicholas M. Greene, M.D. Pp. ix + 143. London: Baillière, Tindall \& Cox. 1963. $56 s$.

The scope and style of this book can be illustrated by a quotation from the preface: 'Because anesthesia is one of the most frequent (and potentially dangerous) acute clinical stresses of iatrogenic origin, the purpose of the present monograph is to summarize the information available on the status of carbohydrate metabolism during clinical anesthesia. This is preceded by a review of present-day concepts of normal carbohydrate metabolism, a review which is not intended to be encyclopedic but which hopefully will be of value to one out of touch with recent developments in biochcmistry'. Most of the commonly used inhalation agents are discussed, although chloroform and ethyl chloride are not included, being considered by the author to be too infrequently used. Altogether there are $11_{3}$ text pages.
References are liberally provided throughout the text and individual articles are very often discussed, sometimes in finicky detail; but there is no attempt at general discussion and few positive conclusions are drawn. The problem of the relationship between the mode of action of inhalation anaesthetics and their effect on carbohydrate metabolism is deliberately avoided. At a more practical level, many common disorders of carbohydrate metabolism which give concern to the anaesthetist in his choice of drugs receive scant mention: for example, the only entry under diabetes mellitus in the index reads 'See insulin'-and the text is no more informative. Islet cell tumours of the pancreas do not appear to be mentioned at all.

The author's presentation does nothing to enliven a subject which most clinical anaesthetists will regard as inherently dull. Although no reader will doubt Dr. Greene's sincere belief in the importance of his subject, many will feel that he has failed to convey precisely wherein this importance lies.

\section{Typhoid Fever and Other Salmonella Infections}

R. L. Huckstep. Pp. 334, illustrated. Edinburgh and London: E. \& S. Livingstone. 1962. $42 \mathrm{~s}$.

One might have imagined until rccently that there was little new to be discovered or written about typhoid fever. It has for long appeared to be one of those uncomplicated and straightforward diseases of which the ætiology and pathology were known and accepted, the diagnosis relatively easy, and treatment simple and effective. Anybody holding these naive views will have to alter them radically as a result of two recent events. One is the publication of this excellent monograph, and the sccond is the Zermatt typhoid epidemic which has amply demonstrated that the disease is no respecter of reputations for cleanliness, that large epidemics may follow apparently minor lapses of routine, and that chloramphenicol is not the universal panacea.

This book, by this unhappy coincidence of events, is extraordinarily timely. It is based upon a very extensive expcrience of typhoid in East Africa, the siatistics of which are set out in a series of appendices. All aspects of the disease are covered from a short historical introduction to a full account of the medical and surgical complications. The sections on laboratory diagnosis include original work on the diazo test in the urine which is shown to be a most useful rapid screening test for the disease. Each chapter has its bibliography and the fact that some references are rather old is at once a tribute to the author's industry and an indication that the recent literature of the disease is somewhat scanty. There is very little to criticize in the text, but one wonders now whether intraperitoneal drips in children are really the best way of parenteral rehydration, when the intravenous drip technique can be acquired quite quickly. There are short chapters also on the paratyphoid fevers and on Salmonella infections, but these are necessarily less comprehensive.

This is altogether a most admirable work, illustrated by most pleasing drawings and charts by $\mathrm{Mr}$. Peter Cull, as well as photographs and X-ray plates, and is thoroughly to be recommended to all who may encounter the disease, and those who would like to prepare themselves in case they do.

\section{Modern Trends in Gynæcology-3}

Edited by R. J. Kellar. Pp. vii +203 , illustrated. London: Butterworths. I963. 50s.

The new format makes this new edition most companionable. The proposal to publish more frequently, though giving more work to the compilers, will enable 
justice to be done to the ever-increasing pace and volume of advancing knowledge. The first edition, once read, remained on the bookshelf, an imposing volume, but at that time the trends were only being born, now they are lively youngsters, pressing in all directions.

Non-invasive cervical carcinoma, which is well described, poses not only questions of definition and diagnosis, but also sets fresh administrative and financial problems for the clinico-pathological gynæcological service, if the maximum number of early diagnoses are to be made and the incidence of the tragic advanced carcinoma is to be decreased.

The rare chorion epithelioma introduces the importance of immunological reactions, yet unrecognized in pregnancy. So far only the blood group factors have been studied. The chemotherapy of this most fatal condition is arrestingly discussed and begins to remove the complete hopelessness we have all felt, particularly when apparently the condition followed an earlier normal confinement.

The chapter on stress incontinence of urine is stimulating and informative, as would be expected from the authorship. The need for time for detailed patient study is amply demonstrated.

The problem of the incompetent cervix is less that of technique than of indication and timing.

Urinary tract infections are assuming much greater importance, as the increasing incidence, difficulties in diagnosis and fatalities are put into focus. This chapter should be read, a 'ban-the-catheter' campaign considered, and other causal factors studied.

The three chapters on biochemistry are most readable and of great importance. The trends covered in the book are too many to review in detail, and I am left pondering on the importance which many have suspected, and the ingenious method of investigation, of the fœto-placental unit.

\section{Physiology of the Circulation in Human Limbs in Health and Disease}

John T. ShePherd, M.D., M.CH., D.SC. Pp. ix + 416 with 179 illustrations. Philadelphia \& London: W. B. Saunders. 1963. 84s.

The author of this book is well known in this country as a former member of the team which, under Professor A. D. M. Greenfield, has done so much excellent work on the peripheral circulation. As Dr. Shepherd points out, much information concerning the circulation in human limbs, with its ramifications in the cardiovascular system as a whole, has accumulated during the past ten years. His book provides a welcome and timely survey of this increasingly complex field.

An attempt has been made to analyse and correlate the large amount of data now available, and for this purpose the material is well presented. After a very brief outline of the methods used in studying the circulation, the book is divided into four sections in terms of the main factors affecting blood vessels. The first three sections cover in turn the nervous, local and humoral control of blood vessels, while the final section describes the modification of blood vessel activity by disease. The various aspects of each subject are discussed in separate chapters within the main sections, and a full and up-to-date list of references is given at the end of each chapter. The relatively new areas in circulatory physiology such as the evidence for receptors in low-pressure zones of the intrathoracic vascular bed concerned with the regulation of muscle blood flow, the response of blood vessels to changes of transmural pressure, and the vascular effects of such substances as 5-hydroxy-tryptamine and bradykinin are well documented. On the clinical side, the circulatory changes in a wide range of conditions from Raynaud's disease osteitis deformans are described.

Dr. Shepherd has aimed at a large audience includi $\widehat{\Phi}_{g}$ the graduate student, the serious investigator and the clinician concerned with diseases affecting the vascular system. He has succeeded to a large extent and âl types of readers will find useful information lucidfy presented.

The book is well illustrated with numerous graple It is generally free of serious printing errors (except an unfortunate chapter heading of idiopathic orthostatic hypertension), and the cost is not prohibitive. By bringing together information on its various aspects, Dr. Shepherd has in this book made a definite contrib世 tion towards the understanding of the human circulation in health and disease.

\section{A Textbook of Surgical Pathology}

Sir Charles Illingworth and Bruce M. Dic 9 th edition. Pp. viii +696 , with 336 illustrations: London: J. \& A. Churchill. 1963. 90s.

The appearance of the ninth edition of Illingworth and Dick's Textbook of Surgical Pathology, with three years of the last edition, testifies to the popularity of this book. It is widely read by those preparing the Final Fellowship examinations, for whom it provides a well-orientated, up-to-date, survey of surgical aspeøs of pathology.

The illustrations and microphotographs, many of which are new, conform to the high standard that his been a feature of previous editions. The provision Df references to original papers and reviews was discontinued with the last edition. However, there p@s 5 i throughout the text names of workers, some at unfamiliar to the reader and serving no useful purise in the absence of any reference to their publications.

The authors devote a chapter to transplantation a preservation of tissues, but, although they state in the preface to this edition that the section on the homogralt reaction has been expanded, in fact this chapter क्षे identical to that in the eighth edition. This seems a pity as the field of homotransplantation is of considerabe current interest to pathologist and surgeon alike, amd rapid strides have been made during the past two gr three years.

These are, however, minor criticisms of an excellent textbook.

\section{Cerebral Palsy in Children and its Treatment}

M. B. Eidinova and Ye. N. Pravdina-vinarskay.

Translated from the Russian. Pp. xv + I illustrated. Oxford, London, New York and Parıs: Pergamon Press. 1963. 70s.

It is inevitable we judge the work from other countries by our own standards. I was at first reminded of Crothers \& Paine's 'Natural History of Cerebral Pals but not for very long. For although this book is baseg on clinical experience there is little factual evidence $\$ 0$ support their glowing claims of success. Mention is made in Chapter 4 of 76 children who were studied a\& treated. Age, sex distribution, educational attainmegr and very detailed information of ætiology is provided but "we found the qualification and classification of their motor disorders extremely complicated' so mugish so that in the almost anecdotal case reports of progress they are impressive without being monvincing. This book reflects the new ground which is being broken ia Russia in this field. The sincerity of their plea forōa hopeful and not defeatist attitude, for active carefulty thought out lines of treatment and not a passive ind ference is reflected in 'the majority of doctors regagd 